\title{
Hydra as a Model for Screening Ec otoxic ological Effects of Plasma-Treated Water
}

\author{
D. Ziuzina, ${ }^{*}$ C. Sarangapani, D. Boehm, \& P. Bourke* \\ School of Food Science and Environmental Health, Environmental Sustainability and Health \\ Institute, Dublin Institute of Technology, Dublin 1, Ireland \\ *Address all correspondence to: Dana Ziuzina or Paula Bourke, School of Food Science and Environmental Health,
Environmental Sustainability and Health Institute, Dublin Institute of Technology, Dublin 1, Ireland;
Tel.: +35314027594, E-mail: dana.ziuzina@dit.ie or paula.bourke@dit.ie
}

\begin{abstract}
Atmospheric cold plasma (ACP) has been widely researched to generate functionalized solutions for decontamination of liquids and wastewater treatment. The focus of this work was to study the ecotoxicological effects of plasma-treated water (PTW) using a free-living brown Hydra as an important and prevalent component of freshwater ecosystems. We obtained PTW by subjecting $25 \mathrm{~mL}$ of sterile deionized water to high-voltage $(80 \mathrm{kV})$ contained ACP treatment for 15 (PTW15) and 25 (PTW25) min. Toxicity measurements were based on the progressive changes in Hydra morphology through a scoring procedure. The effects of PTW on Pseudomonas aeruginosa, Escherichia coli, and Bacillus atrophaeus cells were determined using a broth microdilution method that estimated minimum inhibitory concentration (MIC) and minimum bactericidal concentration (MBC). Results demonstrated that PTW is potentially toxic to biological systems. In Hydra tests, toxic effects were observed for PTW15 and PTW25 at concentrations above $50 \%$ and $25 \%$, respectively. Similarly, PTW25 at a concentration of $25 \%$ is lethal for $P$. aeruginosa and E. coli, whereas an MBC of $37.5 \%$ was obtained for B. atrophaeus. The present investigation demonstrates that Hydra can be used as an additional in vivo tool to monitor the impact of plasma-processed solutions on the aquatic environment.
\end{abstract}

KEY WORDS: atmospheric cold plasma, plasma-treated water, toxicity, Hydra, antimicrobial activity

\section{INTRODUCTION}

Discharge of industrial effluents into the environment is a major cause of water pollution. ${ }^{1}$ A range of industries use chemicals that, due to their complex structure and synthetic origin, are resistant to the currently available wastewater-treatment technologies. ${ }^{2}$ Food-processing industries are often associated with discharge of wastewaters that can hold microbiological and chemical contaminants as well as byproducts derived from various food-processing steps, such as washing, cleaning, and sanitization. ${ }^{3,4}$ Pharmaceutical and personal care products are continuously released into environment in large quantities. ${ }^{5,6}$ Pesticides and their transformation products are bioaccumulative and can often exceed ecotoxic levels for nontarget organisms in aquatic systems. ${ }^{7}$ The lack of efficient water-remediation technologies and wide range of processing operations performed by industries that use potentially ecotoxic substances can significantly impact the natural environment and human health. At- 
mospheric cold plasma (ACP) has been widely researched to generate functionalized solutions for biological decontamination of liquids and as part of advanced oxidative remediation processes to improve wastewater treatment. ACP is composed of several excited atomic, molecular, ionic, and radical species coexisting with numerous reactive species including electrons, positive and negative ions, free radicals, gas atoms, molecules in the ground or excited state, ultraviolet (UV) light, shockwaves, and pyrolysis. All contribute to chemical and physical effects that can subsequently attack pollutant molecules and decompose them into more environmentally friendly products. ${ }^{3,8,9}$ ACP has been successfully applied to remove dyes, ${ }^{10}$ pesticides, ${ }^{11,12}$ aflatoxins, ${ }^{13}$ antibiotics,${ }^{14,15}$ and pathogenic bacteria. ${ }^{4,16,17}$ To date, studies have focused on the decontamination and degradation capacity of ACP against environmental pollutants in aqueous phase; however, very limited studies have been performed to evaluate toxicity of plasma-processed effluents on terrestrial or aquatic environmental indicators. Therefore, the main focus of this work is to evaluate ecotoxicological effects of plasma-treated water (PTW) as a simple model, using the free-living brown Hydra, as an important, environmentally relevant, and prevalent component of freshwater ecosystems. The associated toxic effects of PTW on microbial cells are also evaluated.

\section{METHODOLOGY}

\section{A. Generation of PIW}

We generated PTW using an atmospheric air high-voltage dielectric barrier discharge in-package ACP system that is described in Sarangapani et al. ${ }^{10}$ and is fully characterized in Moiseev et al. ${ }^{18}$ For each experiment, $25 \mathrm{~mL}$ of water was subjected to direct ACP (i.e., samples were placed between aluminum electrodes within plasma discharge) generated at $80 \mathrm{kV}$ with a treatment duration of 15 or 25 min to produce PTW15 and PTW25, respectively. Treatment was carried out at ambient temperature $\left(\sim 20^{\circ} \mathrm{C}\right)$. Samples were stored for $24 \mathrm{~h}$ post-treatment at room temperature. The $\mathrm{pH}$ of each PTW was monitored using a glass electrode $\mathrm{pH}$ meter (Orion Optics UK; Staffordshire, UK) before and after plasma treatment. Nitrate concentrations and hydrogen peroxide concentration in PTW were determined according to the procedure of Boehm et al. ${ }^{19}$ and $\mathrm{Lu}$ et al. ${ }^{20}$

\section{B. Hydra Maintenance and Toxicity Assay}

A free-living brown Hydra was used to study the toxicity of water treated with ACP. Hydra was maintained in Hydra medium (HM) containing $110 \mathrm{mg} / \mathrm{L} \mathrm{N}$-Tris (hydroxymethyl) methyl L-2-aminoethanesulfonic acid (TES) and $147 \mathrm{mg} / \mathrm{L} \mathrm{CaCl}_{2} \cdot 2 \mathrm{H}_{2} 0(\mathrm{pH} 7)$ and was kept at room temperature $\left(\sim 20^{\circ} \mathrm{C}\right)$ in glass beakers that were autoclaved before use. We used deionized water in the preparation of all solutions required throughout the 
study. Hydra was fed daily with freshly hatched Artemia nauplii. After feeding, HM was replaced with fresh medium to avoid culture contamination. ${ }^{21-23}$

Hydra was exposed to untreated deionized water (control), PTW15, or PTW25. Concentrations of PTW were set to $25 \%, 50 \%, 75 \%$, and $100 \%$ using HM. Experiments were conducted using six-well plates. Each well, containing three nonbudding 1-d-starved Hydra, was filled with $2 \mathrm{~mL}$ of either PTW samples or the control. Samples were spiked with TES and $\mathrm{CaCl}_{2}$ to match $\mathrm{HM}$ concentrations of these compounds, and the $\mathrm{pH}$ was adjusted to $7.4 \pm 0.2$ with $1 \mathrm{M} \mathrm{NaOH}$. Before each experiment, samples were passed through 0.2- $\mu \mathrm{m}$ membrane filters. Observations of Hydra were conducted using an Olympus SZ51 stereoscope (Olympus Corporation of the Americas; Center Valley, PA). Results were recorded at 1 and $24 \mathrm{~h}$ after the exposure and daily when required. Toxicity measurements of progressive changes in Hydra morphology were taken based on a scoring procedure using a scale from 10 to 0 devised by Wilby in $1988^{24}$ and reproduced later by Quinn et al. ${ }^{22}$ With this method, a score of 0 corresponds to the highest degree of toxicity. Experiments were performed in triplicate and repeated twice $(n=6)$.

\section{Bacterial Strains, Culture Conditions, and Antimic robial Activity of PIW}

Three single-species test microorganisms, namely, Pseudomonas aeruginosa of American Type Culture Collection (ATCC) 27853, Escherichia coli of ATCC 25922, and Bacillus atrophaeus var. niger of ATCC 9372, obtained from stock cultures of the School of Food, Science, and Environmental Health of the Dublin Institute of Technology, were used to determine antimicrobial activity of PTW. Each bacterium was inoculated in tryptic soy broth (TSB; Biokar Diagnostics; Ireland) and incubated overnight at $37^{\circ} \mathrm{C}$. The density of each overnight culture was adjusted to McFarland 0.5. The minimum inhibitory concentration (MIC) of PTW25 or untreated water for $P$. aeruginosa, E. coli, and B. atrophaeus was determined using a broth microdilution method. ${ }^{25}$ Briefly, PTW was twofold diluted in TSB containing bacterial cells (final cell concentration, $5 \log _{10}$ colony-forming units $/ \mathrm{mL}$ ), with resulting concentration of PTW ranging from $50 \%$ to $0.01 \%$. Controls included PTW or untreated water and TSB without bacterial cells (blank) and TSB with bacterial cells (positive control). Plates were incubated for $24 \mathrm{~h}$ at $37^{\circ} \mathrm{C}$. The MIC of either treated or untreated water for three microorganisms was determined as the lowest concentration showing no turbidity when compared to corresponding blank controls. Plasma-treatment experiments were replicated three times, and two biological replicates were included in each plate. The lowest PTW concentration that inhibited growth of the microorganism was detected by the lack of visual turbidity (matching the corresponding blank control) and was designated MIC. ${ }^{26}$ To determine minimum bactericidal concentration (MBC), $10-\mu \mathrm{L}$ aliquots of MIC and at least two dilutions of higher concentration from each well were plated on tryptic soy agar (TSA Biokar Diagnostics; Ireland) in duplicate, and plates were incubated for $24-48 \mathrm{~h}$ at $37^{\circ} \mathrm{C}$.

Volume 8, Issue 3, 2018 
MBC was determined to be the lowest concentration of PTW at which no bacterial growth was observed.

\section{RESULTS AND DISCUSSION}

Considering potential impacts of industry wastewater effluents on the environment, numerous studies have focused on optimization of plasma technology to achieve efficient biological and chemical pollutant control. Because of the demonstrated performance of plasma processing in pollutant removal, it becomes clear that apart from the biological and chemical degradation capacity of ACP, other important aspects of sustainability including ecotoxicological effects of plasma-processed effluents, and the by-products require holistic assessment. This work investigated ecotoxicological effects of PTW, as a simple matrix, using Hydra as a model invertebrate that represents an important member of the aquatic food web in many freshwater ecosystems. Hydra species requires no license requirements or animal ethics approval, it is associated with low costs, and it is relatively easy to culture and maintain in laboratory environments. ${ }^{27} \mathrm{Hydra}$ has been used to monitor freshwater toxicity and wastewater quality ${ }^{28-30}$ and evaluate toxicity of pharmaceuticals ${ }^{31}$ and nanomaterials. ${ }^{32,33}$ Moreover, it was demonstrated that sensitivity of Hydra to different water sources associated with agricultural and mining sectors was strongly correlated to sensitivity of the Daphnia standard assay. ${ }^{34}$

In this work, the response of Hydra to PTW was measured at the physiological level by evaluating morphological features of the Hydra body and tentacles and scoring from 10 to 0. Results demonstrated that both PTW15 and PTW25 at 100\% were very toxic to Hydra (Fig. 1). Exposure to PTW15 for $1 \mathrm{~h}$ resulted in body elongation (Fig. 1[b]) that was accompanied by slow body reactions, whereas the Hydra body was totally contracted after exposure to PTW25 (Fig. 1[c]), receiving a score of 5 according to the classification scheme (Table 1). Further retaining Hydra in PTW15 and PTW25 at 100\% for $24 \mathrm{~h}$ led to complete disintegration of polyps (Fig. 1[e] and [f], respectively), resulting in a score of 0 for both solutions (Table 1). No alterations in Hydra morphology were observed in control samples after $1 \mathrm{~h}$ and $24 \mathrm{~h}$ (Fig. 1[a] and [d], respectively). PTW15 at a concentration of $75 \%$ was still lethal to Hydra (Fig. 2[a]). Moreover, Hydra exposed to PTW15 at $75 \%$ could not recover after prolonged retention in HM. Morphological features of test animals were altered to a reduced degree after exposure to lower concentrations of PTW15 at 50\% and PTW15 at 25\% receiving scores of 6 and 7, respectively (Fig. 2[b] and [c]). These PTW15 concentrations were sublethal, because all Hydra attained normal morphological appearance and feeding behavior after incubation for 4-5 $\mathrm{d}$ in standard culture conditions. In contrast, all concentrations of PTW25 resulted in a score of $\leq 5$ (Fig. 2[d]-[f]), and Hydra death occurred more frequently during subsequent incubation in HM after exposure to PTW25 at 25\%.

The difference in the response of Hydra to test solutions could be related to the chemical composition of PTW15 and PTW25, with higher concentrations of hydrogen peroxide and nitrate generated after 25 min than after 15 min of treatment (Table 


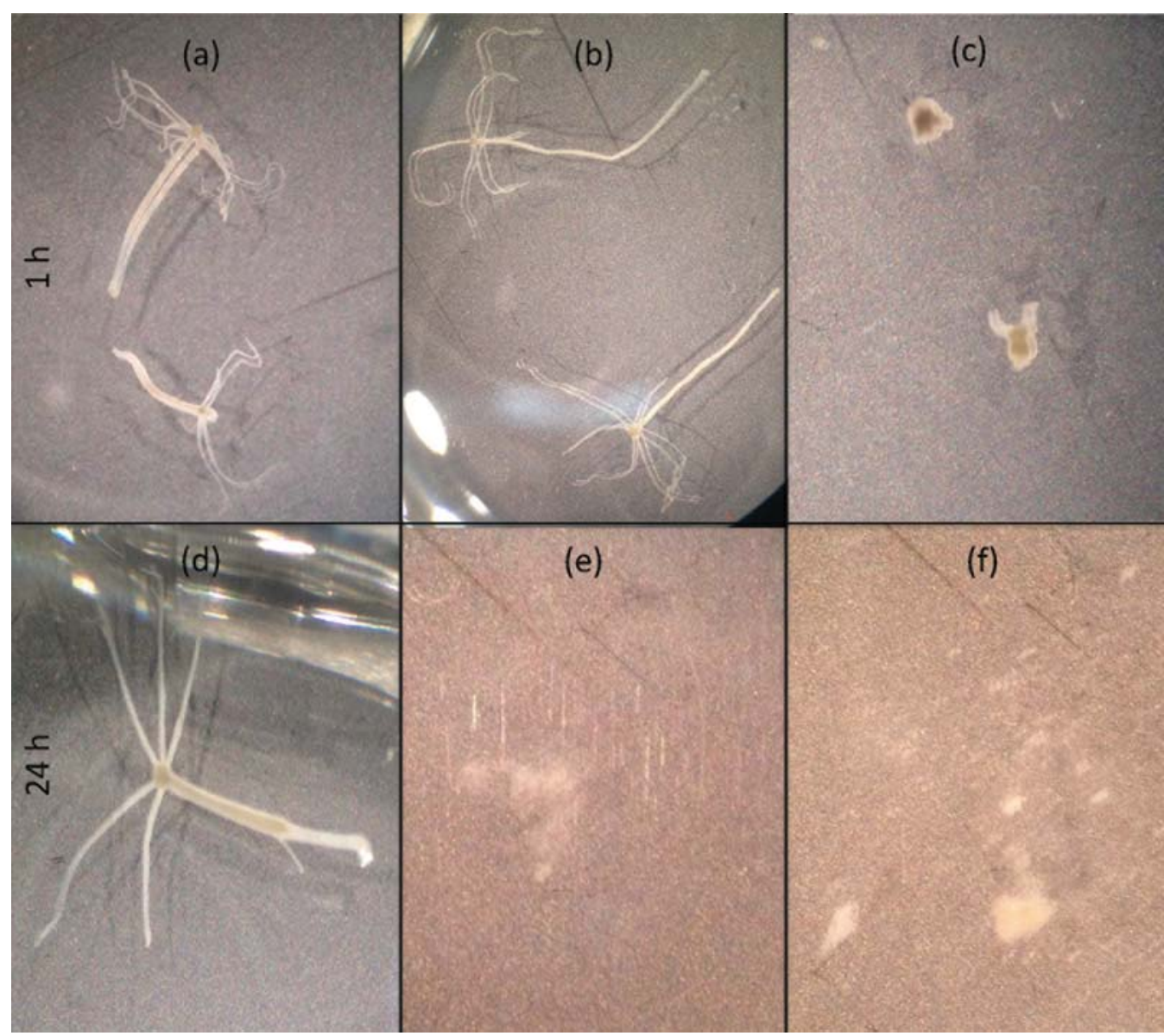

FIG. 1: Images of Hydra reflecting progressive changes in body morphology due to exposure of PTW15 and PTW25 at 100\% recorded after $1 \mathrm{~h}(\mathrm{a}-\mathrm{c})$ and $24 \mathrm{~h}(\mathrm{~d}-\mathrm{f}):(\mathrm{a}, \mathrm{d})$ Control; $(\mathrm{b}, \mathrm{e})$ PTW15; (c, f) PTW25

2). The toxicity of plasma-treated or -activated solutions on cell culture systems have been widely reported, and hydrogen peroxide appears to have a crucial role in causing cytotoxic effects. ${ }^{35}$ Haertel et al. ${ }^{36}$ demonstrated that mainly hydrogen peroxide generated during extended plasma treatments $(5 \mathrm{~min})$ was implicated in mammalian cell death. Boehm et al. ${ }^{19}$ showed that plasma-treated buffer solution inhibited cell growth in a treatment-time-dependent manner, producing a linear correlation to the solutions' peroxide concentration, which correlates with current results. Furthermore, the $\mathrm{pH}$ of water was reduced from $\sim 5.5$ to $\sim 2.79$ and $\sim 2.63$ after 15 and 25 min of treatment, respectively; therefore, to exclude toxic effects of an acidic environment, the $\mathrm{pH}$ of PTW was adjusted to $\sim 7.4$ before each experiment. Preliminary research demonstrated that when Hydra was exposed to PTW generated during shorter plasma durations (1-5

Volume 8, Issue 3, 2018 
TABLE 1: Changes in Hydra morphology due to exposure to PTW15 and PTW25 according to Hydra toxicity classification scheme

\begin{tabular}{|l|c|l|c|}
\hline & PTW Contentration (\%) & Characteristics & Score \\
\hline \multirow{4}{*}{ PTW15 } & 100 & Disintegrated & 0 \\
\cline { 2 - 4 } & 75 & Totally contracted; no visible tentacles & 4 \\
\cline { 2 - 4 } & 50 & Tentacles and body shortened & 6 \\
\hline \multirow{4}{*}{ PTW25 } & 25 & $\begin{array}{l}\text { Shortened tentacles; body slightly } \\
\text { contracted }\end{array}$ & 7 \\
\cline { 2 - 4 } & 100 & Disintegrated & 0 \\
\cline { 2 - 4 } & 75 & Dead but intact (ball-shaped body) & 1 \\
\cline { 2 - 4 } Control & 25 & Totally contracted; tentacles visible & 1 \\
\hline
\end{tabular}

Score 0 corresponds to highest degree of toxicity. Results were recorded after $24 \mathrm{~h}$ from the beginning of the experiment.

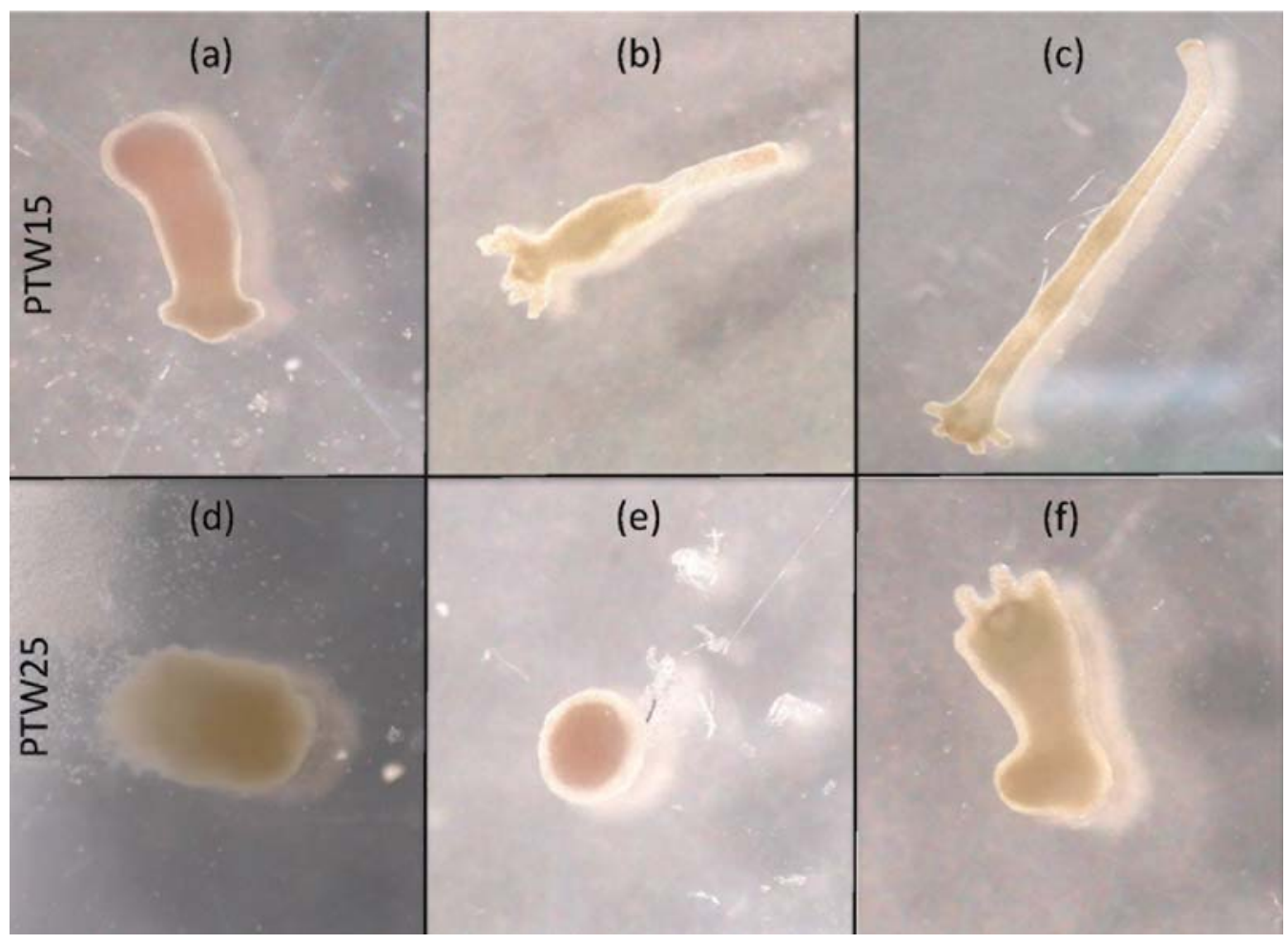

FIG. 2: Images of Hydra reflecting progressive changes in body morphology due to exposure of PTW15 (a-c) and PTW25 (d-f) at concentrations of (a, d) 75\%, (b, e) 50\%, and (c, f) 25\%, recorded after $24 \mathrm{~h}$ 
TABLE 2: Concentration of hydrogen peroxide and nitrate (mM) of PTW

\begin{tabular}{|c|c|c|c|}
\hline & & Method & Concentration \\
\hline \multirow{3}{*}{ PTW15 } & \multirow{2}{*}{ Hydrogen peroxide } & KI & 0.54 \\
\hline & & $\mathrm{TiOSO}_{4}$ & 0.51 \\
\hline & Nitrate & Merck nitrate assay & 0.84 \\
\hline \multirow{3}{*}{ PTW25 } & \multirow{2}{*}{ Hydrogen peroxide } & KI & 0.83 \\
\hline & & $\mathrm{TiOSO}_{4}$ & 1.10 \\
\hline & Nitrate & Merck nitrate assay & 1.30 \\
\hline
\end{tabular}

PTW, Plasma-treated water

min and PTW1-PTW5, respectively) with unadjusted $\mathrm{pH}$, the changes in animal body morphology could be observed within $3 \mathrm{~h}$. After this period, if PTW1 and PTW2 were sublethal to Hydra, exposure to PTW3-PTW5 (with more acidic $\mathrm{pH}$ ) resulted in Hydra death (data not shown). This observation could be useful in terms of selecting plasma treatment parameters, because higher voltage levels and longer treatment durations will likely be associated with low $\mathrm{pH}$ and substantial concentrations of hydrogen peroxide and nitrite/nitrate in plasma-treated solutions, which can potentially affect the ecotoxicity profile for aquatic life.

One of the standard methods for determining toxicity of liquids or single substances is to assess growth inhibition of the bacterium Pseudomonas putida (International Organization for Standardization 10712). ${ }^{37}$ P. putida is commonly used to research toxicity of silver nanoparticles, ${ }^{38,39}$ metals, and pesticides, ${ }^{40,41}$ although the use of other microorganisms, such as E. coli, S. aureus, and Bacillus, has also been reported. ${ }^{42,43}$ In this work, the toxic effect of water subjected to plasma treatment for 25 min was also examined using three bacterial strains, namely, P. aeruginosa, E. coli, and $B$. atrophaeus. Using a broth microdilution assay, MIC and MBC values were established (Table 3). As shown in Fig. 3(a) and (b), PTW25 at concentrations of $\geq 25 \%$ were lethal to both $P$. aeruginosa and $E$. coli (MBC values for both microorganisms corresponded to $25 \%$ of PTW25), which correlated with Hydra response. A slightly lower sensitivity to PTW25 was observed for B. atrophaeus, the growth of which was eliminated at concentrations above $25 \%$ (Fig. $3[\mathrm{c}]$ ). Antimicrobial efficacy of plasmaactivated water has been widely reported showing lethal effects against a wide range of microorganisms. ${ }^{4-46}$ Although this property of plasma-treated solutions may offer a novel and effective decontamination approach for a range of industrial sectors, care must be taken regarding potential unintended adverse effects. Studies by Patange et al. ${ }^{4}$ demonstrated that although ACP treatment could effectively inactivate key indicator microorganisms in model dairy and meat wastewater, prolonged contact with plasma-processed effluents (that retained longer-lived secondary reactive oxygen or nitrogen species) of up to $48 \mathrm{~h}$ was toxic to Daphnia magna. The tests involved in the current work are not widely standardized; however, the demonstrated PTW toxicity in the Hydra test and antimicrobial assay indicates that ecotoxicological impact must be

Volume 8, Issue 3, 2018 
TABLE 3: MIC and MBC values (\%) of PTW25

\begin{tabular}{|l|c|c|}
\hline & MIC & MBC \\
\hline P. aeruginosa & $25 \pm 0$ & $25 \pm 0$ \\
\hline E. coli & $12.5 \pm 0$ & $25 \pm 0$ \\
\hline B. atrophaeus & $18.5 \pm 7.5$ & $37.5 \pm 14.4$ \\
\hline
\end{tabular}

$\mathrm{MBC}$, minimal bactericidal concentration; MIC, minimal inhibitory concentration; PTW, plasma-treated water treated for $25 \mathrm{~min}$.

considered when plasma is used for remedial treatment or functionalization of liquids. This research also supports the possibility of integrating Hydra as a relevant bioindicator, because its sensitivity to PTW was closely correlated with bacterial growth inhibition, and such an assay could therefore be used as an additional biomonitoring tool in a test battery applied for ecotoxicity screening of plasma-processed solutions. In addition, with the Hydra assay, sample toxic effects can be measured at different levels, including acute/chronic toxicity, regeneration and reproduction ability, feeding behavior and attachment to a substrate, and teratogenic and genotoxic effects. ${ }^{22}$ However, to ensure that the Hydra assay realistically reflects toxicity of PTW or plasma-treated industrial effluents, validation studies involving other aquatic invertebrate models and elucidation of PTW ecotoxic profiles are still required. Thus, further studies are warranted to ascertain how to avoid negative impacts of plasma-processed solutions on nontarget aquatic organisms, eliminate environmental pollution, sequentially benefit human health, and progress safe applications of this technology in waterremediation processes.

In summary, this study investigates ecotoxicological effects of PTW using Hydra as a model organism. Based on toxicity tests, we found that water exposed to either 15 or $25 \mathrm{~min}$ of treatment is highly toxic to Hydra. We observed complete disintegration of culture after contact with PTW of $100 \%$ for $24 \mathrm{~h}$. We also found that water exposed to a longer treatment duration of 25 min exhibited higher toxicity in comparison to effects induced by water treated with shorter $(15 \mathrm{~min})$ treatment. These observations were possible when Hydra was exposed to lower concentrations of PTW15 and PWT25 (25\% and 50\%). Sensitivity of Hydra to PTW was correlated with a bacterial growth inhibition assay indicating potential ecotoxicological impacts of plasma-processed solutions. This research highlights the importance of implementing ecotoxicity risk assessments in relevant investigations of novel plasma technologies. We also demonstrate that Hydra could be used as an additional in vivo tool to monitor the impact of plasma-processed solutions on the aquatic environment.

\section{ACKNOWEDGMENTS}

This work was supported by the Research Councils United Kingdom/Science Foundation Ireland (SFI) Grant No. 16/BBSRC/3391 and SFI Grant No. 14/IA/2626. 


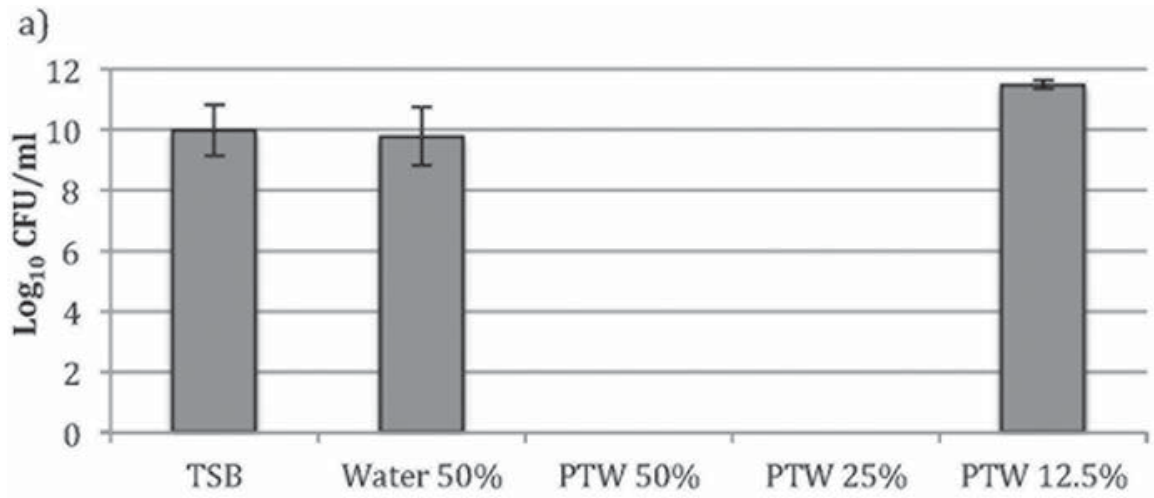

b)
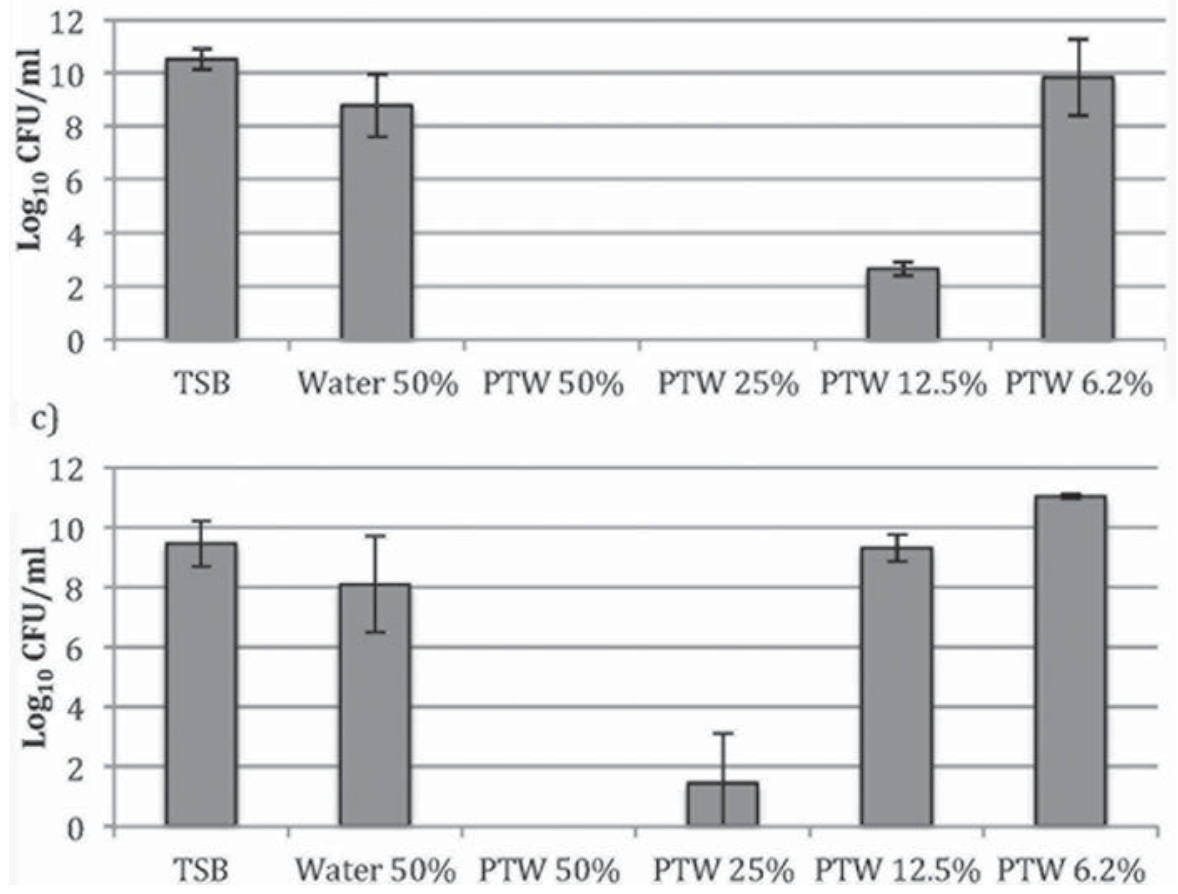

FIG. 3: Effect of PTW25 at different concentrations assessed using the broth microdilution method on (a) P. aeruginosa, (b) E. coli, and (c) B. atrophaeus. (Vertical bars, standard deviation.)

\section{REFERENCES}

1. Haseena M, Malik MF, Javed A, Arshad S, Asif N, Zulfiqar S, Hanif J. Water pollution and human health. Environ Risk Assess Remediat. 2017;1(3):16-9.

2. Robinson T, McMullan G, Marchant R, Nigam P. Remediation of dyes in textile effluent: A critical review on current treatment technologies with a proposed alternative. Bioresour Technol. 2001;77(3):247-55.

Volume 8, Issue 3, 2018 
3. Jiang B, Zheng J, Wu M. Nonthermal plasma for effluent and waste treatment. In: Misra NN, Schluter O, Cullen PJ, editors. Cold plasma in food and agriculture: Fundamentals and applications; Cambridge, MA: Academic; 2016. pp. 309-42.

4. Patange A, Boehm D, Giltrap M, Lu P, Cullen PJ, Bourke P. Assessment of the disinfection capacity and eco-toxicological impact of atmospheric cold plasma for treatment of food industry effluents. Sci Total Environ. 2018;631-632:298-307.

5. Abhilash NT. Pharmaceuticals in environment : A review on its effect. Res J Chem Sci. 2012;2(1):103-5.

6. Tarpani RR, Azapagic A. Life cycle environmental impacts of advanced wastewater treatment techniques for removal of pharmaceuticals and personal care products (PPCPs). J Environ Manage. 2018;215:258-72.

7. Schwarzenbach P, Egli T, Hofstetter TB, von Gunten U, Wehrli B. Global water pollution and human health. 2010;35:109-36.

8. Bourke P, Ziuzina D, Boehm D, Cullen PJ, Keener K. The potential of cold plasma for safe and sustainable food production. Trends Biotechnol. 2018; 36(6):615-25.

9. Jiang B, Zheng J, Qiu S, Wu M, Zhang Q, Yan Z, Xue Q. Review on electrical discharge plasma technology for wastewater remediation. Chem Eng J. 2014;236:348-68.

10. Sarangapani C, Dixit Y, Milosavljevic V, Bourke P, Sullivan C, Cullen PJ. Optimization of atmospheric air plasma for degradation of organic dyes in wastewater. Water Sci Technol. 2017;75(1): 207-19.

11. Sarangapani C, Misra NN, Milosavljevic V, Bourke P, O’Regan F, Cullen PJ. Pesticide degradation in water using atmospheric air cold plasma. J Water Process Eng. 2016;9:225-32.

12. Sarangapani C, O'Toole G, Cullen PJ, Bourke P. Atmospheric cold plasma dissipation efficiency of agrochemicals on blueberries. Innov Food Sci Emerg Technol. 2017;44:235-41.

13. Devi Y, Thirumdas R, Sarangapani C, Deshmukh RR, Annapure US. Influence of cold plasma on fungal growth and aflatoxins production on groundnuts. Food Control. 2017;77:187-91.

14. Kim KS, Kam SK, Mok YS. Elucidation of the degradation pathways of sulfonamide antibiotics in a dielectric barrier discharge plasma system. Chem Eng J. 2015;271:31-42.

15. Magureanu M, Piroi D, Mandache NB, David V, Medvedovici A, Bradu C, Parvulescu VI. Degradation of antibiotics in water by non-thermal plasma treatment. Water Res. 2011;45(11):3407-16.

16. Ziuzina D, Patil S, Cullen PJ, Keener KM, Bourke P. Atmospheric cold plasma inactivation of Escherichia coli, Salmonella enterica serovar Typhimurium and Listeria monocytogenes inoculated on fresh produce. Food Microbiol. 2014;42:109-16.

17. Han L, Patil S, Boehm D, Milosavljević V, Cullen PJ, Bourke P. Mechanisms of inactivation by high-voltage atmospheric cold plasma differ for Escherichia coli and Staphylococcus aureus. Appl Environ Microbiol. 2016;82(2):450-8.

18. Moiseev T, Misra NN, Patil S, Cullen PJ, Bourke P, Keener KM, Mosnier JP. Post-discharge gas composition of a large-gap DBD in humid air by UV-Vis absorption spectroscopy. Plasma Sources Sci Technol. 2014;23(6):065033.

19. Boehm D, Heslin C, Cullen PJ, Bourke P. Cytotoxic and mutagenic potential of solutions exposed to cold atmospheric plasma. Sci Rep. 2016;6:1-14.

20. Lu P, Boehm D, Bourke P, Cullen PJ. Achieving reactive species specificity within plasma-activated water through selective generation using air spark and glow discharges. Plasma Process Polym. 2017;14(8):1-9.

21. Trottier S, Blaise C, Kusui T, Johnson EM. Acute toxicity assessment of aqueous samples using a microplate-based Hydra attenuata assay. Environ Toxicol Water Qual. 1997;12(3):265-271.

22. Quinn B, Gagné F, Blaise C. Hydra, a model system for environmental studies. Int J Dev Biol. 2012;56(6-7-8):613-25.

23. Quinn B, Gagné F, Blaise C. Evaluation of the acute, chronic and teratogenic effects of a mixture of eleven pharmaceuticals on the cnidarian, Hydra attenuata. Sci Total Environ. 2009;407(3):1072-9. 
24. Wilby OK. Utilization of Hydra techniques and results: The Hydra regeneration assay. Proc Assoc FranCaise Teratolog. 1988;92-124.

25. Balouiri M, Sadiki M, Ibnsouda SK. Methods for in vitro evaluating antimicrobial activity: A review. J Pharm Anal. 2016;6(2):71-9.

26. Ramalivhana J, Samie A, Iweriebor B, Uaboi-Egbenni P, Idiaghe J, Momba MNB. Antibacterial activity of honey and medicinal plant extracts against Gram negative microorganisms. Afr J Biotechnol. 2014;13(4):616-25.

27. Holdway DA. Hydra population reproduction toxicity test method. In: Blaise C, Ferard J-F, editors. Small-scale freshwater toxicity investigations. Vol. 1: Toxicity test methods. The Netherlands: Springer; 2005. pp. 395-411.

28. Traversetti L, Del Grosso F, Malafoglia V, Colasanti M, Ceschin S, Larsen S, Scalici M. The Hydra regeneration assay reveals ecological risks in running waters: A new proposal to detect environmental teratogenic threats. Ecotoxicology. 2017;26(2):184-95.

29. Kar S, Aditya AK. Evaluation of freshwater toxicity with Hydra as a test animal. Philippine J Sci. 2007;136(Dec):173-9.

30. Pardos M, Benninghoff C, Guéguen C, Thomas R, Dobrowolski J, Dominik J. Acute toxicity assessment of Polish (waste)water with a microplate-based Hydra attenuata assay: A comparison with the Microtox $^{\circledR}$ test. Sci Total Environ. 1999;243-244:141-8.

31. Quinn B, Gagné F, Blaise C. An investigation into the acute and chronic toxicity of eleven pharmaceuticals (and their solvents) found in wastewater effluent on the cnidarian, Hydra attenuata. Sci Total Environ. 2008;389(2-3):306-14.

32. Murugadas A, Zeeshan M, Thamaraiselvi K, Ghaskadbi S, Akbarsha MA. Hydra as a model organism to decipher the toxic effects of copper oxide nanorod: Eco-toxicogenomics approach. Sci Rep. 2016;6:1-14.

33. Tino A, Ambrosone A, Mattera L, Marchesano V, Susha A, Rogach A, Tortiglione C. A new in vivo model system to assess the toxicity of semiconductor nanocrystals. Int J Biomater. 2011; 2011:792854.

34. Singh P, Nel A. A comparison between Daphnia pulex and Hydra vulgaris as possible test organisms for agricultural run-off and acid mine drainage toxicity assessments. Water SA. 2017;43(2):323-32.

35. Boehm D, Bourke P. Hydrogen peroxide and beyond-The potential of high-voltage plasma-activated liquids against cancerous cells. Anticancer Agents Med Chem. 2017;17:2174.

36. Haertel B, Straßenburg S, Oehmigen K, Wende K, Von Woedtke T, Lindequist U. Differential influence of components resulting from atmospheric-pressure plasma on integrin expression of human HaCaT keratinocytes. Biomed Res Int. 2013;2013(3):761451.

37. Vosylienè MZ. Review of the methods for acute and chronic toxicity assessment of single substances, effluents and industrial waters. Acta Zool Litu. 2007;17(1):3-15.

38. Matzke M, Jurkschat K, Backhaus T. Toxicity of differently sized and coated silver nanoparticles to the bacterium Pseudomonas putida: Risks for the aquatic environment? Ecotoxicology. 2014;23(5):818-29.

39. Mallevre F, Alba C, Milne C, Gillespie S, Fernandes T, Aspray T. Toxicity testing of pristine and aged silver nanoparticles in real wastewaters using bioluminescent Pseudomonas putida. Nanomaterials. 2016;6(3):49.

40. Farré M, Gonçalves C, Lacorte S, Barceló D, Alpendurada MF. Pesticide toxicity assessment using an electrochemical biosensor with Pseudomonas putida and a bioluminescence inhibition assay with Vibrio fischeri. Anal Bioanal Chem. 2002;373(8):696-703.

41. Teodorovic I, Planojevic I, Knezevic P, Radak S, Nemet I. Sensitivity of bacterial vs. acute Daphnia magna toxicity tests to metals. Cent Eur J Biol. 2009;4(4):482-92.

42. Jiang W, Mashayekhi H, Xing B. Bacterial toxicity comparison between nano- and micro-scaled oxide particles. Environ Pollut. 2009;157(5):1619-25.

Volume 8, Issue 3, 2018 
43. Baek YW, An YJ. Microbial toxicity of metal oxide nanoparticles $\left(\mathrm{CuO}, \mathrm{NiO}, \mathrm{ZnO}\right.$, and $\left.\mathrm{Sb}_{2} \mathrm{O}_{3}\right)$ to Escherichia coli, Bacillus subtilis, and Streptococcus aureus. Sci Total Environ. 2011;409(8):1603-8.

44. Kamgang-Youbi G, Herry JM, Meylheuc T, Brisset JL, Bellon-Fontaine MN, Doubla A, Naitali M. Microbial inactivation using plasma-activated water obtained by gliding electric discharges. Lett Appl Microbiol. 2009;48(1):13-8.

45. Traylor MJ, Pavlovich MJ, Karim S, Hait P, Sakiyama Y, Clark DS, Graves DB. Long-term antibacterial efficacy of air plasma-activated water. J Phys D Appl Phys. 2011;44(47):3-7.

46. Oehmigen K, Hähnel M, Brandenburg R, Wilke C, Weltmann KD, von Woedtke T. The role of acidification for antimicrobial activity of atmospheric pressure plasma in liquids. Plasma Process Polym. 2010;7(3-4):250-7. 